\title{
Energy Management through Heat Integration: a Simple Algorithmic Approach for Introducing Pinch Analysis
}

\author{
Nasser A. Al-Azri
}

\begin{abstract}
Department of Mechanical and Industrial Engineering, College of Engineering, Sultan Qaboos University, P.O. Box: 33, PC 123, Al-Khod, Muscat, Sultanate of Oman. Email: nalazri@squ.edu.om.
\end{abstract}

\begin{abstract}
Pinch analysis is a methodology used for minimizing energy and material consumption in engineering processes. It features the identification of the pinch point and minimum external resources. Two common established approaches are used to identify these features: the graphical approach and the algebraic method, which are time-consuming and susceptible to human and calculation errors when used for a large number of process streams. This paper presents an algorithmic procedure to heat integration based on the algebraic approach. The algorithmic procedure is explained in a didactical manner to introduce pinch analysis for students and novice researchers in the field. Matlab code is presented, which is also intended for developing a Matlab toolbox for process integration.
\end{abstract}

Keywords: Algorithmic approach; Heat integration; Pinch analysis; Process integration.

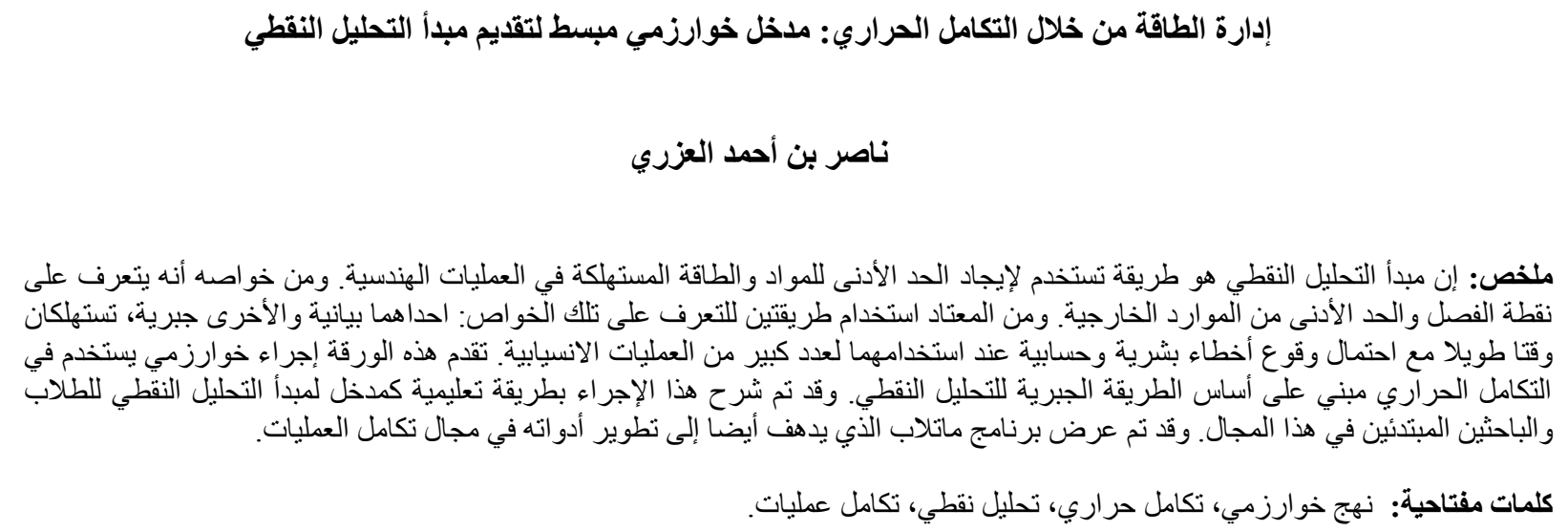

\section{Introduction}

W

ith the rapidly soaring prices of energy, energy management and alternative energy are increasingly becoming more relevant than ever. Moreover, alternatives that were once perceived to be uneconomical have become worth revisiting and investigating.

Heat integration is an energy management strategy that employs pinch analysis to decrease the consumption of energy. It can be implemented either at grass-roots, when the process plant is being designed, or by retrofitting an existing process. Retrofitting, however, has to be economically justifiable as, in many cases, the additional capital is more than the anticipated savings.

Heat integration was introduced by Linnhoff et al. [1], this being the first application of pinch analysis, which is extensively explained and researched in the literature [1-4].

In heat integration, energy from external resources is minimized by using the thermal pinch diagram which targets the optimal matching of hot and cold streams while maintaining thermodynamic feasibility.

The use of the thermal pinch is not merely limited to identifying the maximum potential for heat integration, it can also be used in determining the level of steam mains from the grand composite curve when cogeneration is also considered, along with the production of steam [5-10]. The paper presented here discusses a simple algorithmic approach to the application of pinch analysis. This approach is explained in a step-by-step format to extend the benefit to students and novice researchers. 


\section{Thermal Pinch Diagram}

Before designing the utility system of a processing plant, minimum utility targets need to be determined using the pinch diagram $[11,12]$. For given heat exchange streams, the heat exchanged is calculated from:

$$
\begin{aligned}
& Q_{h}=m_{h} C_{p, h}\left(T_{h}^{s}-T_{h}^{t}\right) \\
& Q_{c}=m_{c} C_{p, c}\left(T_{c}^{t}-T_{c}^{s}\right)
\end{aligned}
$$

where $Q$ is the heat exchanged (in $\mathrm{kW}$ ), $m$ is the mass flow rate (in $\mathrm{kg} / \mathrm{s}$ ), $C_{p}$ is the specific heat capacity (in $\mathrm{kJ} / \mathrm{kg} . \mathrm{K}$ ), $T$ is the temperature (in ${ }^{\circ} \mathrm{C}$ or $\mathrm{K}$ ), while subscripts $h$ and $c$ denote hot and cold respectively, and superscripts $s$ and $t$ denote supply and target respectively.

In a heat-versus-temperature diagram (Figure 1), a hot stream is represented by an arrow whose tail is located at supply temperature $\left(T_{h}^{s}\right)$ and head at target temperature $\left(T_{h}^{t}\right)$ and which is drawn with a slope equal to the product of the stream flow rate and the specific heat $\left(m C_{p}\right)$. These arrows are then arranged in ascending order of their target temperature i.e. by sliding the arrows vertically while maintaining their horizontal projection on the $T$-axis.

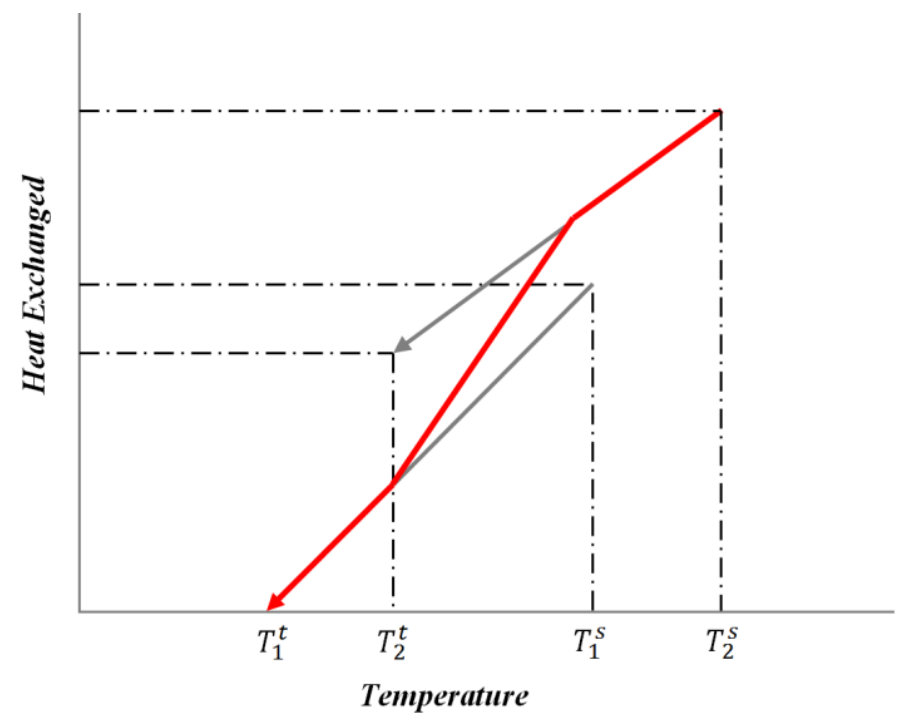

Figure 1. Constructing a hot stream curve using superposition.

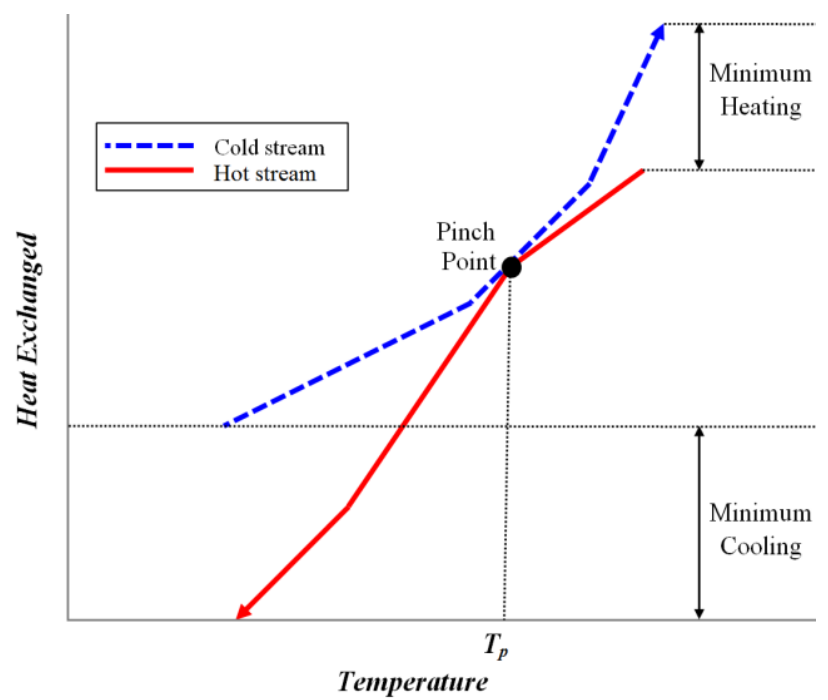

Figure 2. Thermal pinch diagram. 
ENERGY MANAGEMENT THROUGH HEAT INTEGRATION

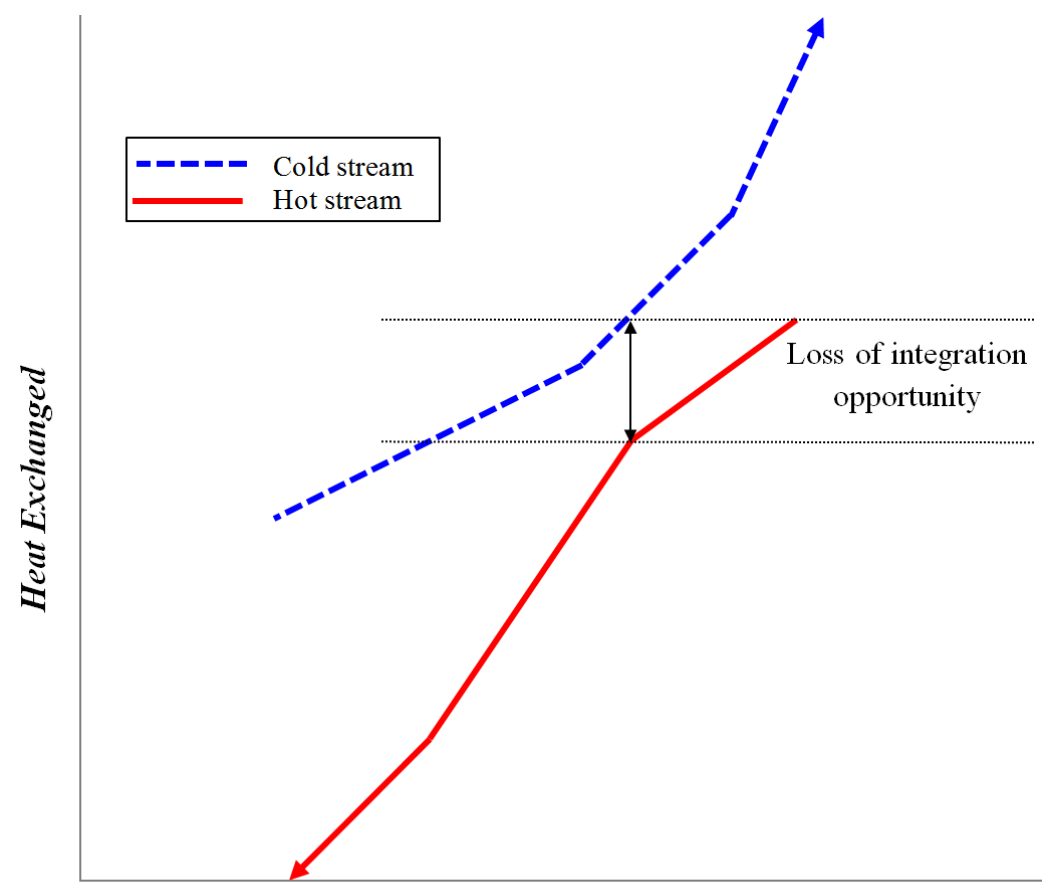

Temperature

Figure 3. Suboptimal integration when streams match beyond pinch point.

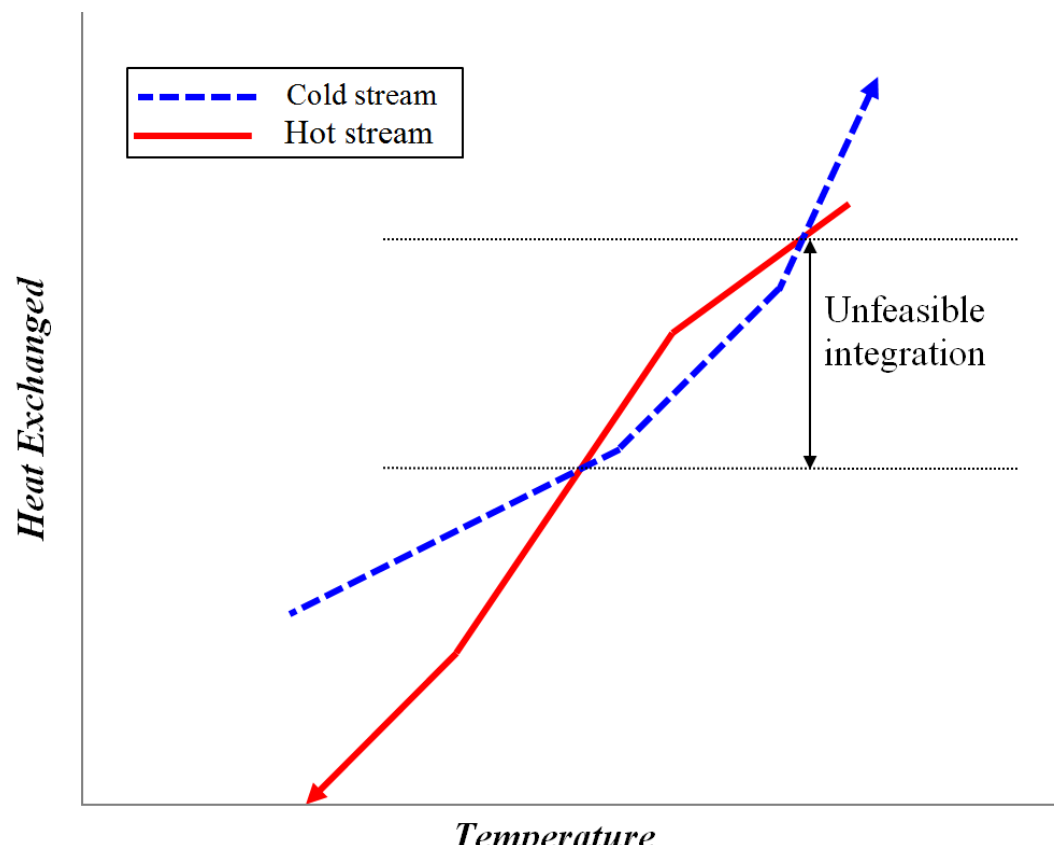

Figure 4. Overlapping implies thermodynamically unfeasible integration.

Cold streams are represented on the diagram using a similar procedure, but they are arranged in ascending order of supply temperature $\left(T_{c}^{S}\right)$.

For both types of streams, if one stream overlaps with another of its kind (cold or hot) in their horizontal projections, the overlapping segments will be represented by a single segment extending from the upper point in the top segment to the lowest point in the lower segment, as shown in Figure 1.

After the two (hot and cold) stream curves have been constructed, the cold stream will then be slid until it touches the hot stream without overlapping, at a point, known as the pinch point, as shown in Figure 2. 
The minimum heating utility, in Figure 2, is the minimum possible heat required from an external source and so is the minimum cooling utility. The pinch point has a very significant meaning, as it represents the temperature value above which any purchase of external cooling indicates a loss of integration opportunity and below which any purchase of external heating indicates a loss of integration opportunity. The loss of integration opportunity results in an increase of external heating and cooling resources, each equivalent to the gap above the pinch point, as shown in Figure 3.

On the other hand, overlapping (Figure 4) implies an exchange of heat from lower temperature to higher temperature, which is thermodynamically unfeasible.

In many cases, the maximum saving obtained from pinch analysis is impractical to achieve because of economic constraints [13]. In such cases, it is used as a benchmark for assessing the level of feasible integration.

\section{The Algorithmic Approach}

In addition to the pinch diagram, the algebraic method is commonly used in heat integration. In this method, hot and cold streams are split into the smallest possible temperature intervals $[11,12]$. The heat requirement for a cold interval is supplied from a hot interval at the same temperature range or higher. The matching starts at the highest interval, and if heat needed by the cold interval at a given range exceeds that offered by the hot one, the excess is to be supplied from an external source. On the other hand, if the heat offered by the hot interval exceeds the requirement of the cold one, the excess is passed to the next pair of intervals. The process continues until the last interval at which, if there is still some excess heat offered by hot streams, it will be discharged to an external cooling source. This procedure is explained here in more detail in an algorithmic format.

The algorithmic approach is not only important for dealing with a large number of streams and hence avoiding the cumbersome graphical method, but is equally important when the matching is to be optimized based on additional practical constraints, such as economic feasibility and distance constraints within the processing plant $[14,15,16]$.

\subsection{Input}

1. $H$ hot streams with source temperature $T_{i}^{s}$, target temperature $T_{i}^{t}$ and thermal capacity $\left(m C_{p}\right)_{i}$ for all $i=1,2,3, \ldots$, $H$.

2. $C$ cold streams with source temperature $T_{j}^{S}$, target temperature $T_{j}^{t}$ and thermal capacity $\left(m C_{p}\right)_{j}$ for all $j=1,2,3, \ldots$ , $C$.

Notice that $T_{i}^{s}>T_{i}^{t}$ for hot streams, and $T_{i}^{s}<T_{i}^{t}$ for cold streams.

3. Minimum temperature gradient $\Delta T_{\text {Min }}$ to assure a sufficient temperature difference for heat transfer.

\subsection{Algorithm}

1. For all $T_{j}^{s}$ and $T_{j}^{t}, j=1,2,3, \ldots C$ (for cold streams)

$$
\begin{gathered}
T_{j}^{S}=T_{j}^{S}+\Delta T_{\text {Min }} \\
T_{j}^{t}=T_{j}^{t}+\Delta T_{\text {Min }}
\end{gathered}
$$

2. Establish the set $T$ of all supply and target temperatures in the problem:

3. Sort $T$ in a descending order such that:

$$
T=\left\{T_{i}^{s} \cup T_{i}^{t} \cup T_{j}^{s} \cup T_{j}^{t}\right\} \text { for } i=1,2,3, \ldots, H \text { and } j=1,2,3, \ldots, C .
$$

$$
T=\left\{T_{i}^{s} \cup T_{i}^{t} \cup T_{j}^{s} \cup T_{j}^{t}\right\}=\left\{T_{1}, T_{2}, T_{3}, \ldots, T_{N}\right\}: T_{1}>T_{2}>T_{3}>\cdots>T_{N}
$$

where $N$ is the total number elements representing the unique set of all supply and target temperatures. In the set $T$, each interval between two consecutive elements can be thought of as a heat exchanger that will integrate hot and cold streams in that interval. Hence, we will have $N-1$ intervals representing $N-1$ heat exchangers.

4. For each hot stream with temperature interval $\left[T_{i}^{t}, T_{i}^{S}\right]$, split the interval into segments such that:

$$
\left[T_{i}^{t}, T_{i}^{S}\right]=\left[T_{i}^{t}, T_{1}^{\prime}\right] \cup\left[T_{1}^{\prime}, T_{2}^{\prime}\right] \cup\left[T_{2}^{\prime}, T_{3}^{\prime}\right] \cup \ldots \cup\left[T_{k}^{\prime}, T_{i}^{S}\right]
$$

where $T_{i}^{t}<T_{1}^{\prime}<T_{2}^{\prime} \ldots<T_{k}^{\prime}<T_{i}^{s}$ and $\left\{T_{1}^{\prime}, T_{2}^{\prime}, T_{3}^{\prime} \ldots T_{k}^{\prime}\right\} \in T$. Then, calculate the total heat to be supplied by each interval $(n)$ by all hot streams whose temperature range coincide with that interval:

$$
Q_{h o t, n}=\Sigma Q_{i, n}=\Sigma\left(m C_{p}\right)_{i, n}\left(T_{u}-T_{l}\right)_{n} \text { for all } i=1,2,3, \ldots, H \text { and } n=1,2,3, \ldots, N-1
$$

where $T_{u}$ and $T_{l}$ are the upper and lower limits of interval $n$, respectively.

5. Perform the same segmentation for each cold stream $\left[T_{j}^{s}, T_{j}^{t}\right]$ by splitting the interval into segments such that:

$$
\left[T_{j}^{s}, T_{j}^{t}\right]=\left[T_{j}^{s}, T_{1}^{\prime}\right] \cup\left[T_{1}^{\prime}, T_{2}^{\prime}\right] \cup\left[T_{2}^{\prime}, T_{3}^{\prime}\right] \cup \ldots \cup\left[T_{k}^{\prime}, T_{j}^{t}\right]
$$

and calculate the heat to be supplied at each interval $(n)$ to all cold streams whose temperature range coincide with that interval:

$$
Q_{c o l d, n}=\Sigma Q_{j, n}=\Sigma\left(m C_{p}\right)_{j, n}\left(T_{u}-T_{l}\right)_{n} \text { for all } j=1,2,3, \ldots, C \text { and } n=1,2,3, \ldots, N-1 .
$$

6. For each interval in $T$, starting in a descending order, integrate heat requirements with cooling requirements. Set $Q_{\text {external heating }}=0$. 
Set $\mathrm{T}_{\mathrm{p}}=-9999$ (for initiation purposes, if retained then integration is not possible).

For $n=1,2,3, \ldots, N-2$ (all intervals except the last)

If $Q_{\text {hot }, n}-Q_{\text {cold }, n}>0$,

pass the surplus heat $\left(Q_{h o t, n}-Q_{\text {cold, },}\right)$ to the next interval:

$Q_{h o t, n+1}=Q_{h o t, n+1}+\left(Q_{h o t, n}-Q_{\text {cold }, n}\right)$.

Else (i.e. $\left.Q_{\text {hot }, n}-Q_{\text {cold }, n} \leq 0\right)$, add the deficit $\left(Q_{\text {cold, },}-Q_{h o t, n}\right)$ to the load to be supplied from an external source: $Q_{\text {external heating }}=Q_{\text {external heating }}+\left(Q_{\text {cold }, n}-Q_{\text {hot }, n}\right)$.

Update the pinch temperature $T_{p}$ :

$T_{p}=T_{n+1}$.

7. For the last interval $(N-1)$

If $Q_{h o t, N-1}-Q_{\text {cold }, N-1} \geq 0$,

the surplus heat $\left(Q_{h o t, N-1}-Q_{\text {cold }, N-1}\right)$ will constitute the external cooling utility:

$Q_{\text {external cooling }}=\left(Q_{\text {hot }, N-1}-Q_{\text {cold }, N-1}\right)$.

Else

add the deficit $\left(Q_{\text {cold }, N-1}-Q_{h o t, N-1}\right)$ to the load to be supplied from an external source:

$Q_{\text {external heating }}=Q_{\text {external heating }}+\left(Q_{\text {cold }, N-1}-Q_{\text {hot }, N-1}\right)$

Let $Q_{\text {external cooling }}=0$.

\section{Illustrative Example}

As an example for showing the application of the algorithm, the process shown in Figure 5 has two coolers and two heaters, with their details shown in Table 1 . In the absence of any heat integration, the total cooling utility is $Q_{\text {external cooling }}=83 \mathrm{MW}$ and the total heating utility is $Q_{\text {external heating }}=56 \mathrm{MW}$.

The minimum temperature difference is $\Delta T_{\min }=10 \mathrm{~K}$. This information is used as input to the algorithmic procedure.

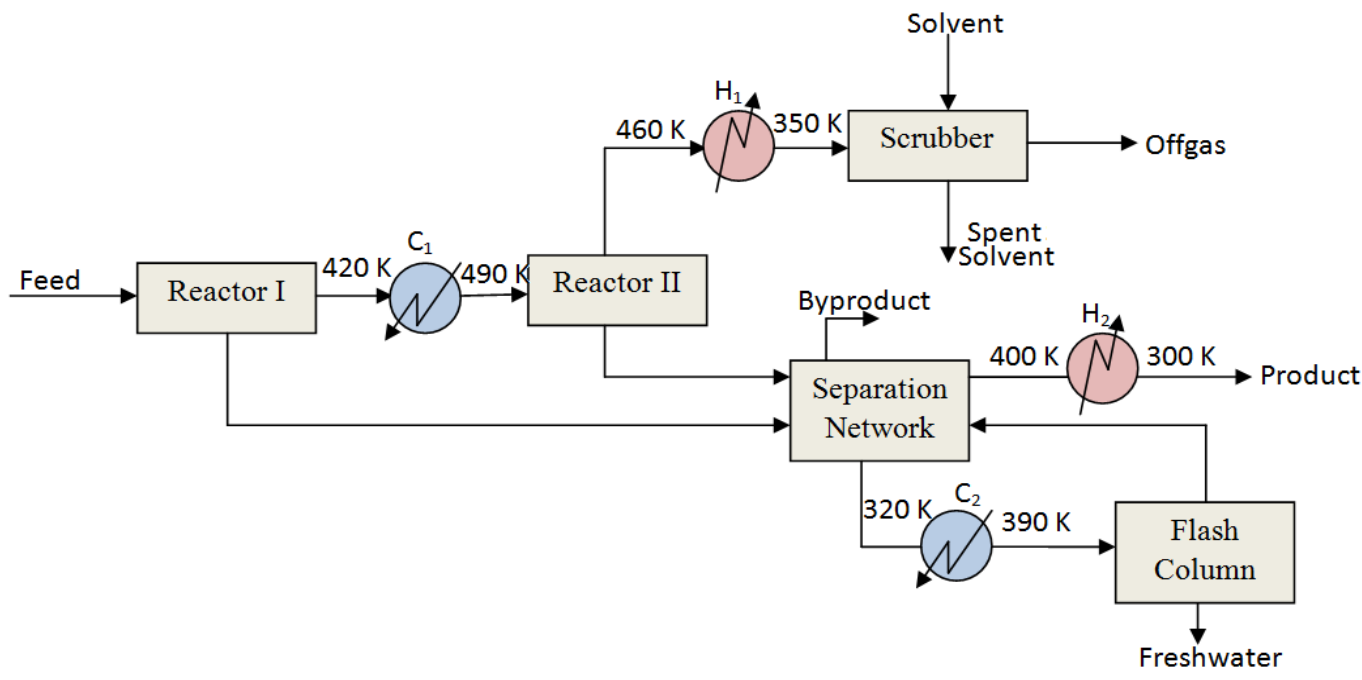

Figure 5. A process with two heaters and two coolers.

Table 1. The total process utility requirement.

\begin{tabular}{|c|c|c|c|c|}
\hline Stream & $\begin{array}{c}m C_{p} \\
(\mathrm{~kW} / \mathrm{K})\end{array}$ & $\begin{array}{c}T^{s} \\
(\mathrm{~K})\end{array}$ & $\begin{array}{c}T^{t} \\
(\mathrm{~K})\end{array}$ & $\begin{array}{c}Q \\
(\mathrm{MW})\end{array}$ \\
\hline$H 1$ & 300 & 460 & 350 & 33 \\
\hline$H 2$ & 500 & 400 & 300 & 50 \\
\hline \multicolumn{5}{|c|}{ Total $\mathbf{8 3}$} \\
\hline$C 1$ & 600 & 420 & 490 & 42 \\
\hline$C 2$ & 200 & 320 & 390 & 14 \\
\hline
\end{tabular}


1. The cold stream supplies and target temperatures are altered as given in Table 2 after considering the minimum temperature difference:

Table 2. Modified cold stream temperatures.

\begin{tabular}{|c|c|c|c|c|}
\hline Stream & $\begin{array}{c}m C_{p} \\
(\mathrm{~kW} / \mathrm{K})\end{array}$ & $\begin{array}{c}T^{s} \\
(\mathrm{~K})\end{array}$ & $\begin{array}{c}T^{t} \\
(\mathrm{~K})\end{array}$ & $\begin{array}{c}Q \\
(\mathrm{MW})\end{array}$ \\
\hline$C 1$ & 600 & 430 & 500 & 42 \\
\hline$C 2$ & 200 & 330 & 400 & 14 \\
\hline
\end{tabular}

2. Establish the set $T$ of all supply and target temperatures: $T=\{460,350,400,300,430,500,330\}$.

3. Sort elements in $T$ in a descending order: $T=\{500,460,430,400,350,330,300\}$. There are seven elements $(N=7)$ and six intervals from [500, 460] to [330, 300].

4. Split the hot streams as given in Table 3 to evaluate utility requirements at each interval:

Table 3. Hot stream temperatures.

\begin{tabular}{|c|c|c|c|c|}
\hline $\begin{array}{c}\text { Stream } \\
(i, n)\end{array}$ & $\begin{array}{c}m C_{p} \\
(\mathrm{~kW} / \mathrm{K})\end{array}$ & $\begin{array}{c}T^{s} \\
(\mathrm{~K})\end{array}$ & $\begin{array}{c}T \\
(\mathrm{~K})\end{array}$ & $\begin{array}{c}Q \\
(\mathrm{MW})\end{array}$ \\
\hline $\boldsymbol{H 1}$ & $\mathbf{3 0 0}$ & $\mathbf{4 6 0}$ & $\mathbf{3 5 0}$ & $\mathbf{3 3}$ \\
\hline$H_{1,2}$ & & 460 & 430 & 9 \\
$H_{1,3}$ & & 430 & 400 & 9 \\
$H_{1,4}$ & & 400 & 350 & 15 \\
\hline $\boldsymbol{H 2}$ & $\mathbf{5 0 0}$ & $\mathbf{4 0 0}$ & $\mathbf{3 0 0}$ & $\mathbf{5 0}$ \\
\hline$H_{2,4}$ & & 400 & 350 & 25 \\
$H_{2,5}$ & & 350 & 330 & 10 \\
$H_{2,6}$ & & 330 & 300 & 15 \\
\hline
\end{tabular}

The second subscript is the interval number in the set of the six intervals. The total heat to be discharged at each interval (see Table 4):

Table 4. Heat discharged.

\begin{tabular}{|c|c|c|c|c|c|c|}
\hline $\begin{array}{c}\text { Interval } \\
(n)\end{array}$ & $\begin{array}{c}{[500,460]} \\
1\end{array}$ & $\begin{array}{c}{[460,430]} \\
2\end{array}$ & $\begin{array}{c}{[430,400]} \\
3\end{array}$ & $\begin{array}{c}{[400,350]} \\
4\end{array}$ & $\begin{array}{c}{[350,330]} \\
5\end{array}$ & $\begin{array}{c}{[330,350]} \\
6\end{array}$ \\
\hline $\begin{array}{c}Q_{\text {hot, } n} \\
(\mathrm{MW})\end{array}$ & 0 & 9 & 9 & 40 & 10 & 15 \\
\hline
\end{tabular}

5. Repeat step 4 for the cold streams (see Table 5):

Table 5. Cold stream temperatures.

\begin{tabular}{|c|c|c|c|c|}
\hline $\begin{array}{c}\text { Stream } \\
(i, n)\end{array}$ & $\begin{array}{c}m C_{p} \\
(\mathrm{~kW} / \mathrm{K})\end{array}$ & $\begin{array}{c}T^{s} \\
(\mathrm{~K})\end{array}$ & $\begin{array}{c}T \\
(\mathrm{~K})\end{array}$ & $\begin{array}{c}Q \\
(\mathrm{MW})\end{array}$ \\
\hline $\boldsymbol{C 1}$ & $\mathbf{6 0 0}$ & $\mathbf{4 3 0}$ & $\mathbf{5 0 0}$ & $\mathbf{4 2}$ \\
\hline$C_{1,2}$ & & 430 & 460 & 18 \\
$C_{1,1}$ & & 460 & 500 & 24 \\
\hline $\boldsymbol{C 2}$ & $\mathbf{2 0 0}$ & $\mathbf{3 3 0}$ & $\mathbf{4 0 0}$ & $\mathbf{1 4}$ \\
\hline$C_{2,5}$ & & 330 & 350 & 4 \\
$C_{2,4}$ & & 350 & 400 & 10 \\
\hline
\end{tabular}

The total heat needed at each interval (see Table 6):

Table 6. Heat requirement.

\begin{tabular}{|c|c|c|c|c|c|c|}
\hline $\begin{array}{c}\text { Interval } \\
(n)\end{array}$ & {$[500,460]$} & {$[460,430]$} & {$[430,400]$} & {$[400,350]$} & {$[350,330]$} & {$[330,350]$} \\
5 & 2 & 3 & 4 & 5 \\
\hline $\begin{array}{c}Q_{\text {cold } n} \\
\text { (MW) }\end{array}$ & 24 & 18 & 0 & 10 & 4 & 0 \\
\hline
\end{tabular}


6. Start the integration step from interval 1 . If the heat needed by the cold interval $\left(Q_{\text {cold, } n}\right)$ exceeds that offered by the hot one $\left(Q_{h o t, n}\right)$, the excess is added to the load supplied externally $\left(Q_{\text {external heating }}\right)$. On the other hand, if the heat offered by the hot interval $\left(Q_{h o t, n}\right)$ exceeds the requirement of the cold one $\left(Q_{c o l d, n}\right)$, the excess is passed to the next hot interval which is updated, $\left(Q_{h o t, n}=Q_{h o t, n}+Q_{h o t, n-1}\right)$.

Table 7. Heat requirement.

\begin{tabular}{|c|c|c|c|c|c|c|}
\hline $\begin{array}{c}\text { Interval } \\
(n)\end{array}$ & $\begin{array}{c}{[500,460]} \\
1\end{array}$ & $\begin{array}{c}{[460,430]} \\
2\end{array}$ & $\begin{array}{c}{[430,400]} \\
3\end{array}$ & $\begin{array}{c}{[400,350]} \\
4\end{array}$ & $\begin{array}{c}{[350,330]} \\
5\end{array}$ & $\begin{array}{c}{[330,350]} \\
6\end{array}$ \\
\hline $\begin{array}{c}Q_{\text {hot }, n} \\
(\mathrm{MW})\end{array}$ & 0 & 9 & 9 & 40 & 10 & 15 \\
\hline $\begin{array}{c}Q_{\text {hot, },} \\
\text { (updated) }\end{array}$ & - & 9 & 9 & 49 & 49 & 60 \\
\hline $\begin{array}{c}Q_{\text {cold, } n} \\
(\mathrm{MW})\end{array}$ & 24 & 18 & 0 & 10 & 4 & 0 \\
\hline$Q_{\text {hot, },-Q_{\text {cold, } n}}$ & -24 & -9 & 9 & 39 & 45 & 60 \\
\hline$Q_{\text {external heating }}$ & 24 & 33 & 33 & 33 & 33 & 33 \\
\hline $\begin{array}{c}T_{p} \\
(\mathrm{~K})\end{array}$ & 500 & 430 & 430 & 430 & 430 & 430 \\
\hline
\end{tabular}

7. In the last interval as given in Table 7 , one can see that $Q_{\text {external cooling }}=\left(Q_{\text {hot, } 6}-Q_{\text {cold, },}\right)=60 \mathrm{MW}$ and $Q_{\text {external heating }}=$ $33 \mathrm{MW}$ and the pinch point is the lower bound of the second interval, $T_{p}=430 \mathrm{~K}$.

The main principle of the algorithm is the fact that heat at the highest temperature is of the best quality, as it can always cover heat requirements at all intervals below it. Hence, heat requirements are sorted by temperature so that heat requirements at higher temperatures are given priority for supply over those at lower temperatures. The surplus from high intervals can then be moved to the next lower, but not vice versa.

From step 6, at the highest interval, one can see that there is a deficiency (heat requirement, $Q_{\text {cold }}>0$ ) but no heat supply $\left(Q_{h o t}=0\right)$. This requirement must be covered by an external source since no heat is available at that temperature or higher. At the next temperature interval, heat supply is less than heat required $\left(Q_{h o t}<Q_{\text {cold }}\right)$, so the available supply will only cover part of the requirement and the remaining part must be covered from an external supply since all other supplies are at lower intervals. At the third interval, there is a heat supply but no heat required $\left(Q_{h o t}>0, Q_{\text {cold }}=0\right)$. This supply can be passed on to the next lower interval. At intervals 4, 5 and 6 , the heat supply is more than required and so heat will be passed on to the lower interval until $60 \mathrm{MW}$ accumulates at the lowest interval, which then needs to be covered by an external cooling source.

The pinch point is the temperature above which no cooling utilities should be supplied externally and below which no heating utilities should be purchased. So as long as heat is supplied from an external source at a given interval, pinch point cannot be higher than the lower bound of that interval. In this procedure, pinch point is maintained as the lower bound of the last interval at which heat was supplied externally, which is the lower bound of the second interval in the example.

The output of this example can be verified using the graphical approach described in the introduction. Figure 6 shows the pinch diagram using the graphical method, where the hot stream composite is matched against the cold one while maintaining the thermodynamic constraints of heat flow. The horizontal projection of both streams on one another represents the maximum integration i.e. heat flow from hot streams to the cold ones.

\section{Practical Example}

A practical example for which the graphical method is quite cumbersome is the two sets of 20 hot streams and 15 cold streams in a process, as presented in Table 8.

This process as is, without integration, requires 1628.5 MW of cooling utility and $1451.1 \mathrm{MW}$ of heating utility. Upon the implementation of the above algorithm using Matlab (see Appendix), and with $\Delta T_{\min }=10 \mathrm{~K}$, the cooling utility can be minimized to $204.6 \mathrm{MW}$ and the heating utility can potentially be minimized to $27.2 \mathrm{MW}$ with the pinch point at $899 \mathrm{~K}$. 
NASSER A. AL-AZRI

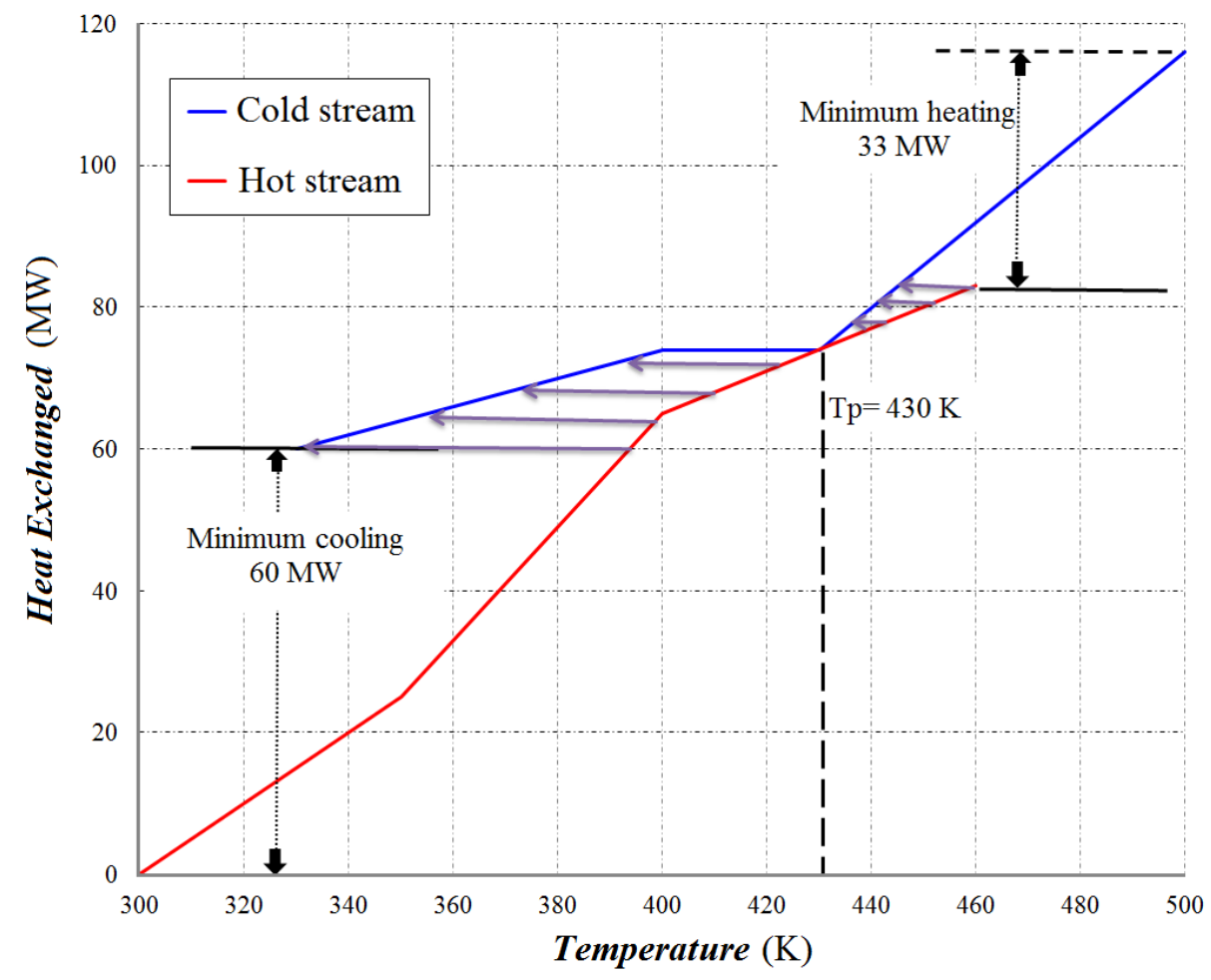

Figure 6. Thermal pinch diagram for the illustrative example.

The same results are shown in the graphical pinch diagram (Figure 7), where the horizontal projection of hot and cold streams represents the maximum integration, of 1423.9 MW exchanged from the hot streams to the cold ones.

Table 8. Hot and cold streams from a large process.

\begin{tabular}{cccc|cccc}
\hline $\begin{array}{c}\text { Hot } \\
\text { Stream }\end{array}$ & $\begin{array}{c}m C_{p} \\
(\mathrm{~kW} / \mathrm{K})\end{array}$ & $\begin{array}{c}T^{s} \\
(\mathrm{~K})\end{array}$ & $\begin{array}{c}T^{r} \\
(\mathrm{~K})\end{array}$ & $\begin{array}{c}\text { Cold } \\
\text { Stream }\end{array}$ & $\begin{array}{c}m C_{p} \\
(\mathrm{~kW} / \mathrm{K})\end{array}$ & $\begin{array}{c}T^{s} \\
(\mathrm{~K})\end{array}$ & $\begin{array}{c}T^{t} \\
(\mathrm{~K})\end{array}$ \\
\hline$H 1$ & 346 & 501 & 359 & $C 1$ & 502 & 314 & 401 \\
$H 2$ & 169 & 590 & 405 & $C 2$ & 549 & 263 & 577 \\
$H 3$ & 794 & 714 & 565 & $C 3$ & 396 & 244 & 370 \\
$H 4$ & 240 & 600 & 463 & $C 4$ & 666 & 192 & 356 \\
$H 5$ & 414 & 626 & 272 & $C 5$ & 738 & 378 & 540 \\
$H 6$ & 445 & 899 & 846 & $C 6$ & 493 & 260 & 527 \\
$H 7$ & 401 & 679 & 382 & $C 7$ & 518 & 342 & 685 \\
$H 8$ & 394 & 785 & 743 & $C 8$ & 319 & 502 & 846 \\
$H 9$ & 496 & 634 & 351 & $C 9$ & 282 & 491 & 553 \\
$H 10$ & 244 & 663 & 398 & $C 10$ & 380 & 499 & 681 \\
$H 11$ & 770 & 455 & 304 & $C 11$ & 484 & 127 & 207 \\
$H 12$ & 383 & 737 & 694 & $C 12$ & 717 & 277 & 378 \\
$H 13$ & 551 & 513 & 507 & $C 13$ & 412 & 192 & 357 \\
$H 14$ & 722 & 619 & 559 & $C 14$ & 512 & 608 & 737 \\
$H 15$ & 803 & 863 & 741 & $C 15$ & 601 & 597 & 939 \\
$H 16$ & 473 & 905 & 625 & & & & \\
$H 17$ & 543 & 817 & 640 & & & & \\
$H 18$ & 606 & 744 & 548 & & & & \\
$H 19$ & 674 & 568 & 298 & & & & \\
$H 20$ & 216 & 891 & 523 & & & & \\
\hline
\end{tabular}




\section{ENERGY MANAGEMENT THROUGH HEAT INTEGRATION}

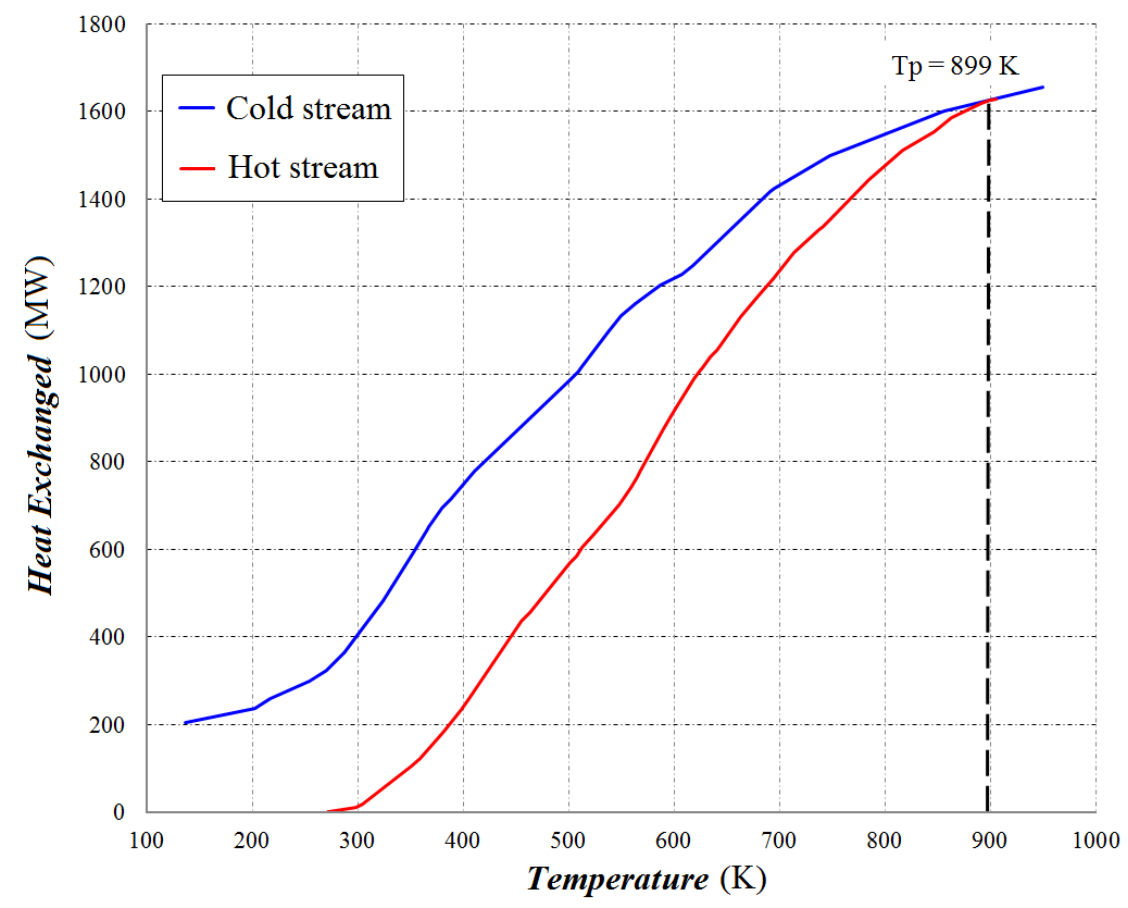

\section{Conclusion}

Figure 7. Thermal pinch diagram for the practical example.

An algorithmic approach to pinch analysis has been presented in an algorithmic setting which is helpful for introducing pinch analysis as well as handling large problems and hence eliminating human errors encountered with the graphical method. Two examples have been solved and compared to the graphical method to show the applicability of the algorithm.

The presented algorithm is based on segmenting heat supply and requirement by temperature. Integration then starts from the highest interval and moves downwards by covering deficiencies from external sources, and then passing the surplus down to the next interval until the surplus at the last interval sums up the external cooling needs. The pinch point is maintained as the lower bound of the last interval at which heat was supplied externally. The results obtained from this procedure conform to those obtained using the graphical method.

A further development of the algorithm could be through the introduction of additional constraints such as minimum allowable distance and amount of heat between heat exchangers.

\section{References}

1. Linnhoff, B., Townsend, D.W., Boland, D., Hewitt, G.F., Thomas, B.E.A., Guy, A.R. and Marsland, R.H. User Guide on Process Integration for the Efficient Use of Energy. Institute of Chemical Engineers (IChemE), Warwickshire, UK, 1982.

2. Hohman, E.C. Optimum Networks for Heat Exchanger. University of Southern California, Los Angeles, 1971.

3. Linnhoff, B. and Hindmarsh, E. The pinch design method for heat exchanger networks. Chemical Engineering Science, 1983, 38(5), 745-763.

4. Umeda, T., Itoh, J. and Shiroko, K. A thermodynamic approach to the synthesis of heat integration systems in chemical processes. Computers and Chemical Engineering, 1979, 3, 273-282.

5. Raissi, K. Total Site Integration, PhD Thesis, Department of Process Integration, University of Manchester Institute of Science and Technology, Manchester, UK, 1994.

6. Mavromatis, S.P. and Kokossis, A.C. Conceptual optimization of utility networks for operational variations. I. Targets and level optimization. Chemical Engineering Science, 1998, 53(8), 1585-1608.

7. Varbanov, P.S., Doyle, S. and Smith, R. Modeling and optimization of utility systems. Transactions of IChemE, 2004, 82(A5), 561-578.

8. Beangstrom, S.G. and Majozi, T. A process integration technique for steam system synthesis involving multiple levels. The $11^{\text {th }}$ International Symposium on Process Systems Engineering, Singapore, 2012.

9. Chen, C., Lin, C. and Lee, J. Retrofit of steam power plants in a petroleum refinery. Applied Thermal Engineering, 2013, 61,7-16.

10. Sun, L., Doyle, S. and Smith, R. Process utility systems conceptual design by graphical methods. Computer Aided Chemical Engineering, 2014, 33, 1813-1818. 
11. El-Halwagi, M.M. Pollution Prevention Through Process Integration. Academic Press, San Diego, California, USA, 2003.

12. El-Halwagi, M.M. Process Integration. Academic Press, San Diego, California, USA, 2006.

13. Al-Azri, N. Process Integration and Utility System Optimization, PhD Thesis, Department of Chemical Engineering, Texas A\&M University, Texas, USA, 2008.

14. Al-Azri, N., Al-Thubaiti, M. and El-Halwagi, M. An algorithmic approach to the optimization of process cogeneration, Clean Technologies and Environmental Polices, 2008, 11(3), 329-338.

15. Navarro-Amorós, M., Caballero, J., Ruiz-Femenia, R. and Grossmann, I. An alternative disjunctive optimization model for heat integration with variable temperatures. Computers and Chemical Engineering, 2013, 56, 12-26.

16. Onishi, V., Ravagnani, M. and Caballero, J. Simultaneous synthesis of work exchange networks with heat integration. Chemical Engineering Science, 2014, 112, 87-107.

\section{Appendix: Matlab Code}

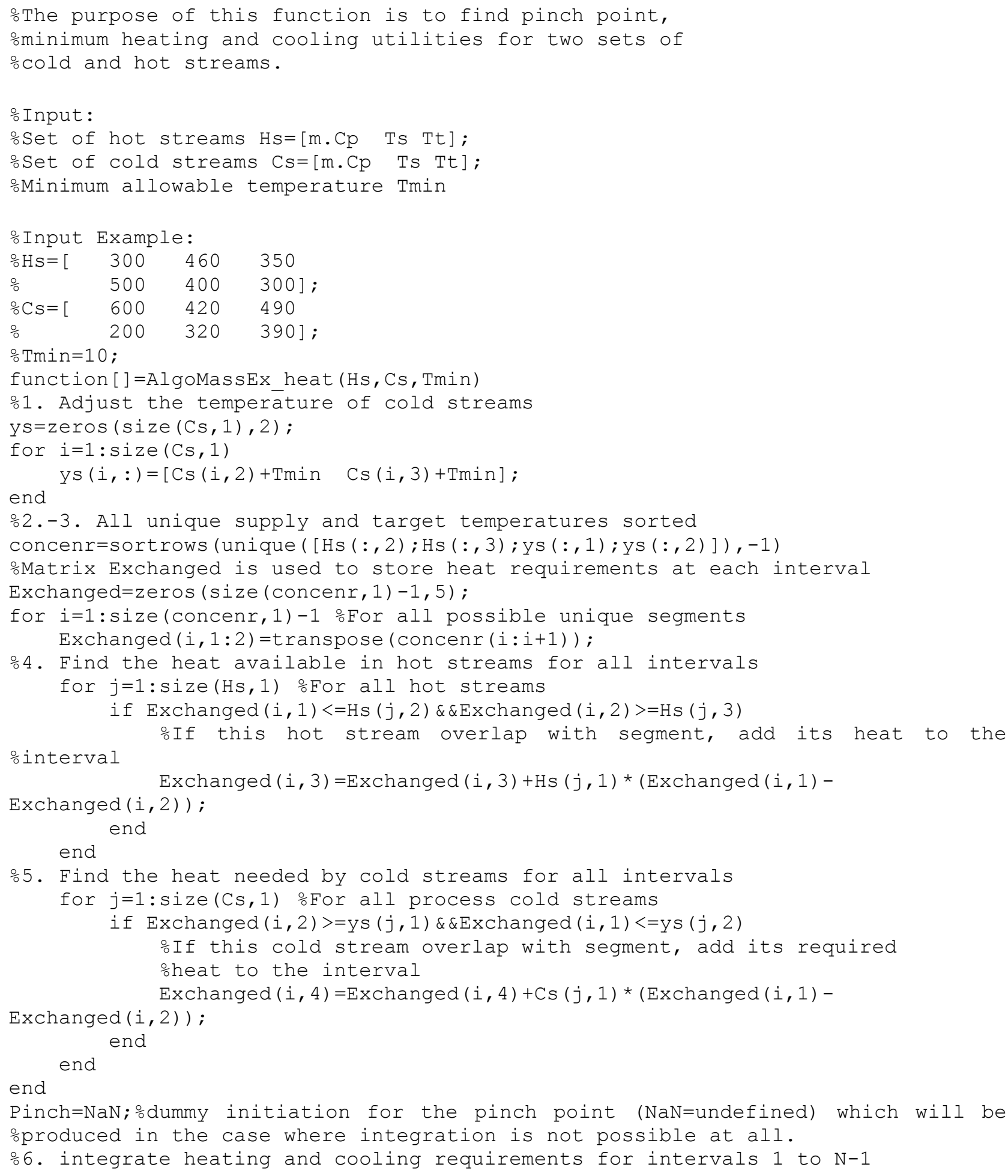




\section{ENERGY MANAGEMENT THROUGH HEAT INTEGRATION}

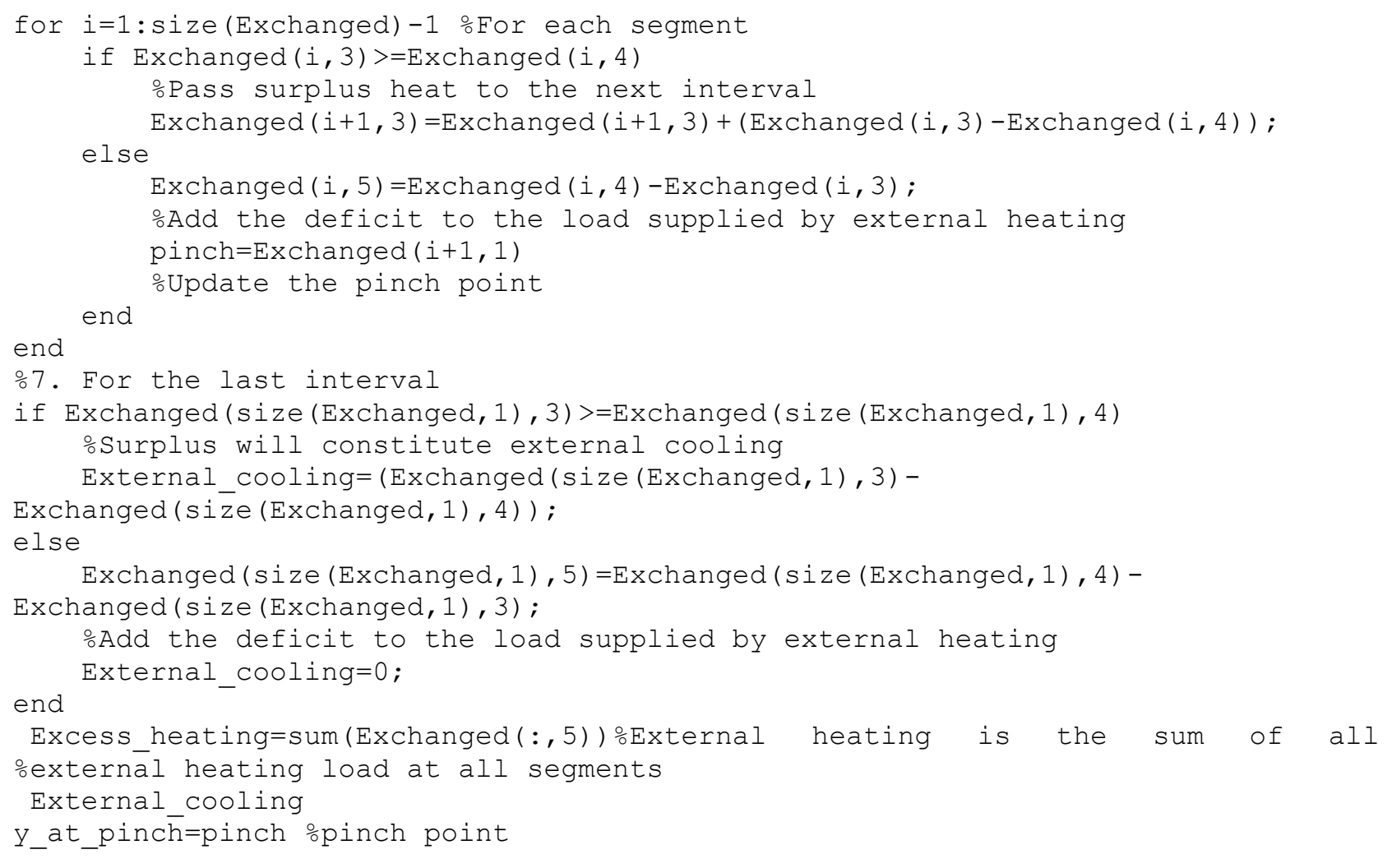

Received 3 June 2014

Accepted 27 February 2015 